\title{
Fatigue Behavior of Prestressed Concrete Beams under Overload
}

\author{
Qin Xin ${ }^{1,2 *}$, Yuanming Dou ${ }^{1,2}$ and Sha $\mathrm{Li}^{3}$ \\ ${ }^{1}$ School of Civil Engineering, Hebei University of Technology, Tianjin 300401, China \\ ${ }^{2}$ Civil Engineering Technology Research Center of Hebei Province, Tianjin 300401, China \\ ${ }^{3}$ Graduate School of Science and Engineering, Yamaguchi University, Ube, 755-8611, Japan
}

Received 24 May 2017; Accepted 18 September 2017

\begin{abstract}
The random and varied longitudinal and transverse loading positions of vehicles exert different effects on the fatigue performances of bridges. Consequently, bridge components exhibit different structural failure mechanisms under heavy duty. To determine the effect of heavy duty on the fatigue performance of beams, this study conducted a fatigue test with load amplitude and loading method as variables. First, 10 test beams were designed, and the static test was performed on three of the beams. Second, fatigue amplitude was determined on the basis of static test results and actual vehicle data. Constant and variable amplitude loading tests were conducted on the seven remaining beams. Finally, the material properties of prestressed concrete beams under long-term heavy vehicular load were analyzed. Research results demonstrate that all test beams suffered from fatigue failure cause by brittle fracture that initiate in the bottom beam reinforcement. The strain variation of all test beams can be divided into three stages. The residual strain of steel bars is positively correlated with the number of loads. Under the fixed low-load limit, the fatigue life of test beams is shortened by $95 \%$ and $98 \%$, respectively, when the upper load limit is 0.75 and 0.8 times of the ultimate load. The fatigue life of test beams under the low-high loading process is $46 \%$ shorter than that under the high-low loading process. The conclusions can provide theoretical references for the late performance evaluation and maintenance of prestressed concrete beams.
\end{abstract}

Keywords: Heavy duty, Overload, Prestressed concrete beams, Fatigue test

\section{Introduction}

Expressways are crucial for economic development in various regions in China [1]. Prestressed concrete structures are more extensively utilized in the design and construction of expressway bridges than ordinary reinforced concrete structures. In addition, these structures are a main component of long-span bridges in China given that they can maximize material properties, improve crack resistance and stiffness, and increase the structural span of structures or members [2, 3]. The application of high-strength concrete and reinforcement decreases the dead weight and dead load of prestressed concrete members. Consequently, the proportion occupied by fatigue load increases. The common application of the design theory of ultimate state places many bridge members in a high-stress state; thus, fatigue life is significantly affected, and fatigue failure is aggravated [4, 5]. Therefore, research on the mechanism and properties of prestressed concrete beams under fatigue load is necessary.

Existing experimental analyses on fatigue damage mechanisms have mainly focused on reinforced concrete beams under non-overloaded conditions [6, 7]. However, total vehicle and axial loads frequently exceed the design load of a highway bridge during actual service [8-10]. Heavy duty refers to the drastic deterioration of pavement

*E-mail address: xinqin0902@163.com

ISSN: $1791-2377$ C 2017 Eastern Macedonia and Thrace Institute of Technology. All rights reserved. doi:10.25103/jestr.104.17 performance under high traffic volume or under cumulative equivalent standard axle that exceeds the general level; heavy duty is mainly manifested as vehicle overload [11]. Overload indicates that a highway bridge is loaded with vehicles beyond its maximum carrying capacity [12]. Each pass of a vehicle over a bridge is equal to one loading and unloading cycle. Cyclic loading easily causes various damages to bridge structures. A survey on vehicle overload behaviors revealed that the service life of highways, which are designed to serve for approximately 15 years, will be shortened to 1 year if all vehicles carry loads that twice that of their maximum carrying capacity. Worldwide, many highway bridges, which were constructed with large amounts of funds, exhibit subsidence, hollow spots, tracking, bridge pavement damage, and plate rupture during their first and two years of service. Defects that are caused by vehicle overload will significantly affect the safety and reliability of existing bridge structures and incur high repair costs $[13,14]$ Hence, the effective maintenance of highway bridge structures, accurate prediction of the fatigue service life of bridges, and elucidation of the bridge failure mechanism caused by vehicle overload is issues that require urgent resolution.

In the present study, ten pieces of test-scale prestressed concrete beams for use in the reconstruction and extension project of a highway were designed on the basis of similarity theory and damage mechanics. These beams were used to evaluate the fatigue performances of prestressed concrete beams under different heavy duties. 


\section{State of the art}

Many studies have investigated bridge structural damages caused by heavy duty. Walter, Kilareki studied the effects of heavy duty and overload limit, as well as established the definitions of these two variables [15]. Nevertheless, their study only included qualitative interpretations without quantitative analyses. Zhou et al. established a universal simulation platform by using a numerical analysis system. To predict the global dynamic response of bridges under load, they then used the platform to develop a bridge traffic model under completely coupled combined and ultimate loads. Nonetheless, they did not thoroughly discuss the fatigue damage mechanism of the bridge structure [16]. Han et al. developed advanced analytical software for bridge interaction and numerically studied the dynamic responses of a highway bridge with medium span under selected traffic conditions. The feasibility of the developed system for predicting the dynamic responses of the bridge structure under normal load was verified by its results with existing provisions [17]. However, this system is inapplicable to overload conditions. Han, W et al. installed a health monitoring system on highway bridges in service to enable the statistical analysis of extra-heavy duty sample data and consequently obtained the characteristics of vehicle parameters. To analyze ultralimit conditions, they also constructed a random traffic flow-bridge model by using a computer program coupled with a vibration analysis module [18]. Unfortunately, they did not explore the stress behaviors of bridge structures under ultralimit service conditions. Huang et al. collected traffic compositions and load parameters in the main highways of Guangdong Province, analyzed the adverse effects of overload transportation on highway facilities and traffic safety, and proposed suggestions for highway management and facilities [19]. Nevertheless, their conclusions still showed regional limitation. Moreover, their studies did not explore the bridge damage mechanism caused by overload, thereby failing to offer specific recommendations for component design.

Existing studies have mainly focused on the dynamic responses of bridge structures under overload and heavy duty through data collection and computer simulation. Nevertheless, none of these studies has explored the mechanism underlying fatigue damage under overload and heavy duty, and their conclusions are unsupported by test data. Some scholars have conducted experimental research on the fatigue performance of structures under overload conditions. Zhang et al. used a group of hydraulic jacks to simulate vehicle overloads of 196 and $294 \mathrm{kN}$ under one lane and dual lane loadings, respectively. Their predicted global dynamic responses of bridge under load demonstrated that the measured loading capacity of the test bridge is considerably higher than the design capacity, whereas the measured transverse coupling stiffness of bridges changed slightly from the designed transverse coupling stiffness [20]. Although hydraulic jacks can be used for the accurate application of a preset load on a bridge, this loading method disagrees with the actual stress mode of bridge structures and cannot reflect the cyclic characteristics of vehicle load. Oudah et al. discussed the damage accumulation of reinforced concrete beams caused by different prestress levels under fatigue load and found that damage accumulation is unrelated to prestress level [21]. Moreover, although they emphasized the use of the prestress degree of materials as a variable, they only analyzed the performance deterioration of bridge structures under load. Thus, they failed to disclose the direct relationship between fatigue load and the performance deterioration of reinforced concrete beams. Barbara Charalambidi applied two different load amplitudes to reinforced concrete beams and compared the corresponding service life of the beams. They concluded that the fatigue life of beams under high load would be shortened However, the applied high load in the experiment did not accurately reflect overload risks given that it was controlled within the maximum limit of industrial standard [22].

Although most scholars have focused on the characteristics of heavy duty and the dynamic responses of reinforced concrete beams under a specific load, few have discussed fatigue performance deterioration under different overload amplitudes particularly that of prestressed concrete components under variable amplitude overload. In the present study, the failure mode and material properties of highway bridge structures under constant and variable amplitude loadings were discussed in accordance with the characteristics of heavy duty and with the applied load of different overload amplitudes as the variable. The relationship between the load and fatigue performance deterioration of the beam structure was constructed. The conclusions of this study can provide references for the performance evaluation and maintenance of the highway bridge.

The remaining sections of this study are divided as follows. The static and fatigue tests based on a reasonable scale model, as well as the derivation of ultimate bearing capacity and fatigue service life, are discussed in Section 3. An analysis of the crack propagation, midspan deflection, and strain development of steel bars under different loading amplitudes based on test data is presented in Section 4. The last section summarizes the entire research and provides relevant conclusions.

\section{Methodology}

\subsection{Design of the model beams}

A prestressed hollow beam was used as a prototype for the construction of a scale model. The actual cross-sectional dimensions of the hollow-plate girder are shown in Figure 1.

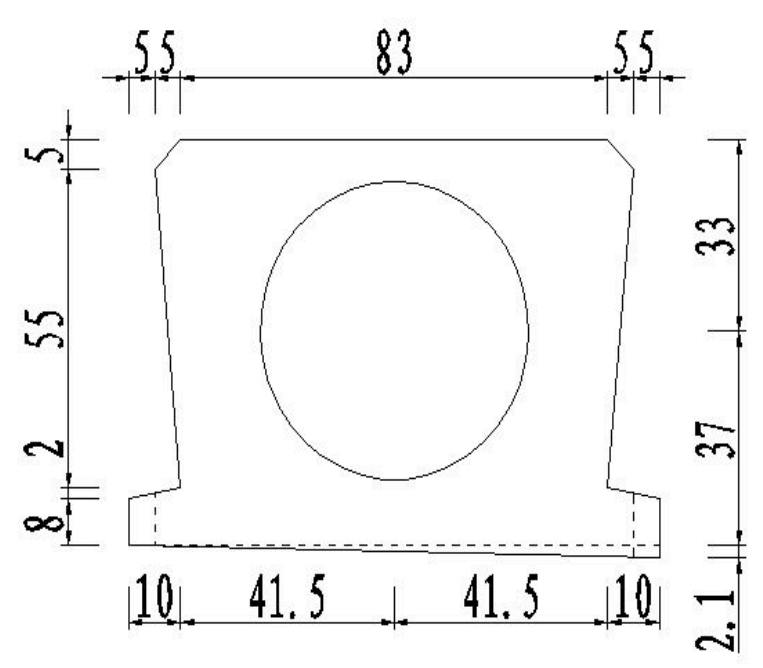

Fig. 1. Cross-sectional dimensions of the prototype hollow beam (16 m)

The test beam models prepared through pretensioning method on a reduced scale of $1: 4$. The solid rectangular section of the model beams was $\mathrm{b} \times h=200 \mathrm{~mm} \times 180 \mathrm{~mm}$, 
and the calculated length of the beams was $3.7 \mathrm{~m}$. The concrete material of the model was same as that of the original structure. The concrete strength grade was $\mathrm{C} 40$, and the thickness of the protective layer was $30 \mathrm{~mm}$. The diameter of the aggregate used in the concrete did not exceed $20 \mathrm{~mm}$. The prestressed steel wires utilized in the prestressed steel bars were $\phi 7$, and the tension stress was 0.73 times that of the standard value for tensile strength. The maximum strengthening value did not exceed 1.05 times of the standard value. HPB300 steel bars with $6 \mathrm{~mm}$ diameter were selected as common bars. Iron wire (12\#) with $2.6 \mathrm{~mm}$ diameters were selected as stirrups. The spacing was 100 $\mathrm{mm}$, and the spacing close to supports was narrowed to 50 $\mathrm{mm}$. The measured values of the material strength are presented in Table 1 and Table 2.

\subsection{Static test}

The static test was conducted with three pieces of test beams to obtain the cracking and ultimate loads of the beam structure. The static test results are shown in Table 3.

Table 1. Measured compressive concrete strength

\begin{tabular}{c|c|c|c|c}
\hline Block types & Size (mm) & Number & $\begin{array}{c}\text { Cube crushing strength } \\
\text { (MPa) }\end{array}$ & $\begin{array}{c}\text { Axial compressive } \\
\text { strength (MPa) }\end{array}$ \\
\hline Test cube & $150 \mathrm{~mm} \times 150 \mathrm{~mm} \times 150 \mathrm{~mm}$ & 3 & 41.6 & - \\
Prism block & $150 \mathrm{~mm} \times 150 \mathrm{~mm} \times 150 \mathrm{~mm}$ & 3 & - & 29.8 \\
\hline
\end{tabular}

Table 2. Measured steel strength

\begin{tabular}{c|c|c|c|c}
\hline Steel types & Diameter $(\mathbf{m m})$ & Yield strength (MPa) & Ultimate strength (MPa) & Elongation (\%) \\
\hline Prestressed wire & 7 & 1410 & 1,603 \\
Regular reinforcement & 6 & 316 & 420 \\
\hline
\end{tabular}

Table 3. Static test results

\begin{tabular}{c|c|c|c|c|c|c}
\hline \multirow{2}{*}{ Type of test } & \multirow{2}{*}{ No. of beams } & \multirow{2}{*}{ Failure mode } & \multicolumn{3}{|c|}{$M_{\text {cr }}(k N \cdot m)$} & \multicolumn{2}{c}{$M_{\mathrm{u}}(k N \cdot m)$} \\
\cline { 3 - 6 } & & & Test & 11.1 & 11.5 & 22.7 \\
Static test & S1 & Bending failure & 12.4 & 11.5 & 23.5 \\
& S2 & Bending failure & 13.2 & 11.5 & 23.8 \\
& S3 & Bending failure & 23.8 & 23.8 \\
\hline
\end{tabular}

\subsection{Fatigue test}

The fatigue test was performed with seven test beams on the MTS electro hydraulic servo-controlled fatigue-testing machine. The loading frequency was $2 \mathrm{~Hz}$. A schematic of the test is shown in Figure 2.

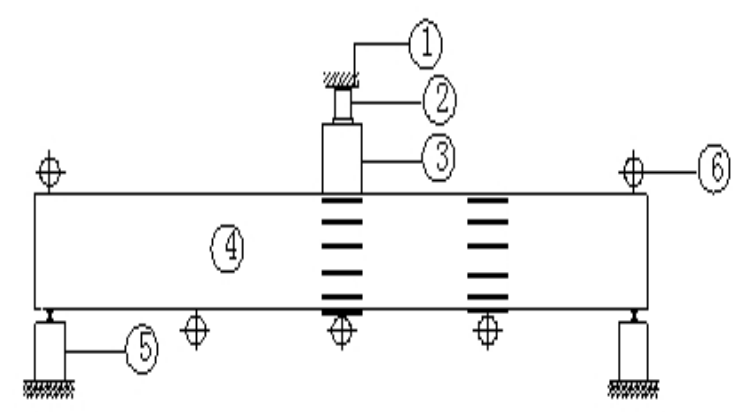

(1) Reaction beam, (2) Pressure sensor, (3) Hy Hydraulic jacks, (4) Test beam, (5) Support pier, (6) Motion detector

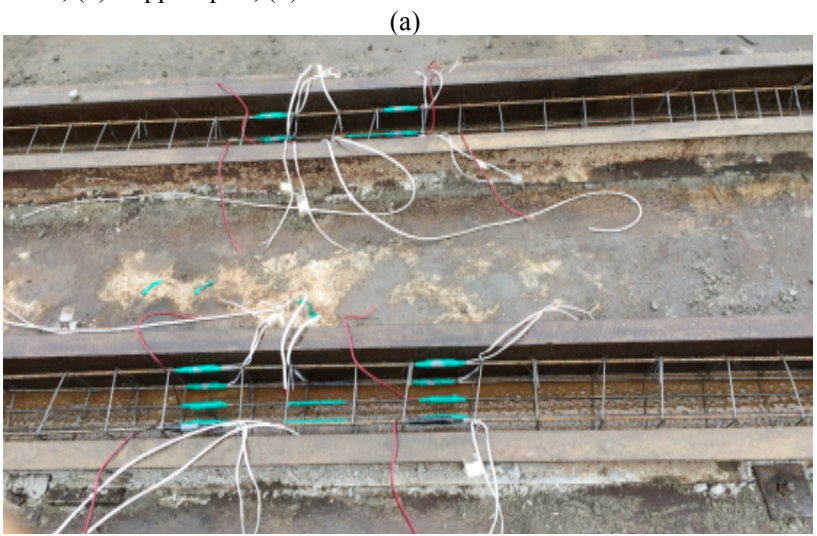

(b)

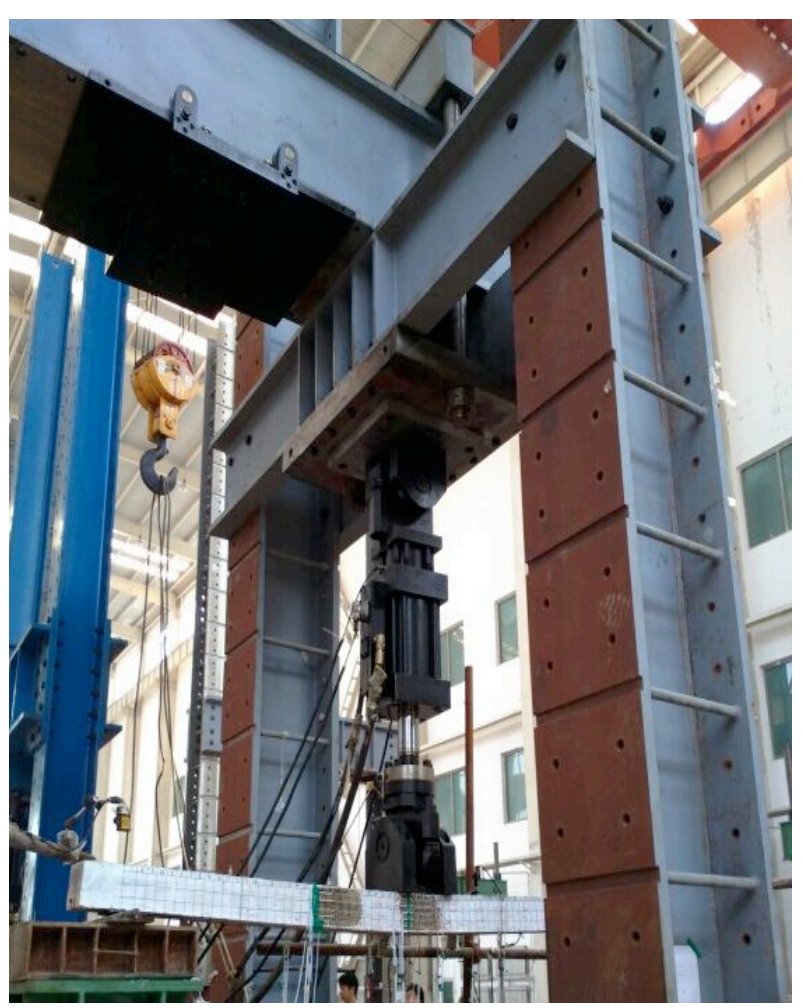

(c)

Fig. 2. Fatigue test and measurement

Many studies have investigated vehicle load [3, 23]. In the literature, the fatigue load amplitude of the tests is determined on the basis of the statistical analysis of the expressway vehicle load [24-25]. In this study, the lower 
limit of the fatigue load was 0.15 times the value of the ultimate load to account for the self-weight of the structure, bridge deck pavement, situation of vehicle travels, and laboratory conditions. According to the static test results and existing load statistics, the maximum loads of the constant amplitude fatigue test were $0.5,0.6,0.7,0.75$, and $0.8 M_{\mathrm{u}}$. The two-level variable amplitudes, fatigue test results, and fatigue failure modes are listed in Table 4.

Table 4. Service life of model beams in fatigue tests

\begin{tabular}{|c|c|c|c|c|c|c|}
\hline \multirow[b]{2}{*}{ Test } & \multirow{2}{*}{$\begin{array}{l}\text { Be } \\
\text { am } \\
\text { No. } \\
\end{array}$} & \multicolumn{3}{|c|}{ Loading system $(\mathrm{kN})$} & \multirow{2}{*}{$\begin{array}{c}\text { Fatigue life or } \\
\text { ultimate strength under } \\
\text { static load } \\
\end{array}$} & \multirow[b]{2}{*}{ Failure mode } \\
\hline & & $\begin{array}{r}\text { Lower } \\
\text { load limit }\end{array}$ & $\begin{array}{r}\text { Upper } \\
\text { load limit }\end{array}$ & $\begin{array}{l}\text { Amplitu } \\
\text { de }\end{array}$ & & \\
\hline \multirow{5}{*}{$\begin{array}{l}\text { Constant } \\
\text { amplitude fatigue } \\
\text { test }\end{array}$} & $\mathrm{C} 1$ & 4 & 12 & 8 & $\begin{array}{l}N \geq 2000000 \\
P_{\mathrm{u}}=20 \mathrm{kN}\end{array}$ & $\begin{array}{c}\text { Undamaged after } 2 \text { million cycles of } \\
\text { loads and subsequent bending failure } \\
\text { under static load }\end{array}$ \\
\hline & $\mathrm{C} 2$ & 4 & 14 & 10 & $\begin{array}{l}N \geq 2000000 \\
P_{\mathrm{u}}=24 k N\end{array}$ & $\begin{array}{c}\text { Undamaged after } 2 \text { million cycles of } \\
\text { loads and subsequent bending failure } \\
\text { under static load }\end{array}$ \\
\hline & $\mathrm{C} 3$ & 4 & 16 & 12 & $\begin{array}{l}N \geq 2000000 \\
P_{\mathrm{u}}=27 \mathrm{kN}\end{array}$ & $\begin{array}{c}\text { Undamaged after } 2 \text { million cycles of } \\
\text { loads and subsequent bending failure } \\
\text { under static load }\end{array}$ \\
\hline & $\mathrm{C} 4$ & 4 & 18 & 14 & $\begin{array}{c}N=102000 \\
\text { Brittle damage }\end{array}$ & $\begin{array}{l}\text { Breakage of steel bars in the pure } \\
\text { bending section }\end{array}$ \\
\hline & $\mathrm{C} 5$ & 4 & 20 & 16 & $\begin{array}{c}N=51000 \\
\text { Brittle damage }\end{array}$ & $\begin{array}{l}\text { Breakage of steel bars in the pure } \\
\text { bending section }\end{array}$ \\
\hline $\begin{array}{l}\text { Two-level } \\
\text { variable }\end{array}$ & $\begin{array}{l}\mathrm{LH} \\
1\end{array}$ & 10 & 16 & - & $\begin{array}{l}N=1080000 \\
\text { Brittle damage }\end{array}$ & $\begin{array}{l}\text { Breakage of steel bars in the pure } \\
\text { bending section }\end{array}$ \\
\hline $\begin{array}{l}\text { amplitude fatigue } \\
\text { test }\end{array}$ & $\begin{array}{l}\mathrm{HL} \\
1\end{array}$ & 16 & 10 & - & $\begin{array}{l}N \geq 2000000 \\
P_{\mathrm{u}}=21.4 k N\end{array}$ & $\begin{array}{c}\text { Undamaged after } 2 \text { million cycles of } \\
\text { loads and subsequent bending failure } \\
\text { under static load }\end{array}$ \\
\hline
\end{tabular}

\section{Result Analysis and Discussion}

\subsection{Results of constant-amplitude fatigue tests 4.1.1 Fatigue Failure mode}

All test beams underwent bending failure, and all failures started with the fatigue fracture of nonprestressed reinforced bars. Analyzing the effective data of typical test beams revealed that fatigue fracture mainly occurred in a section with major fracture. Crack initiation and propagation accelerated significantly under increasing load. Table 4 shows that the fatigue life of $\mathrm{C} 4$ and $\mathrm{C} 5$ is $95 \%$ and $98 \%$ shorter than that of $\mathrm{C} 1$, respectively. The fatigue life of $\mathrm{LH}$ is $46 \%$ shorter than that of HL. Despite the discreteness and difference of specimens, the residual ultimate bearing capacities of C2 and C3 increased by 24 and $27 \mathrm{kN}$, respectively, after 2 million repetitive loading cycles. This result indicated that the residual static bearing capacity of undamaged beams under fatigue load is immune to the loading process.

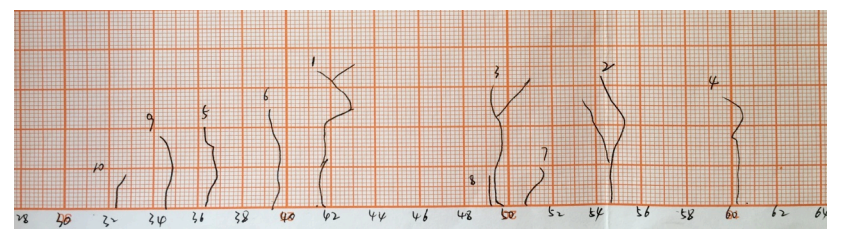

(a) $\mathrm{C} 2$

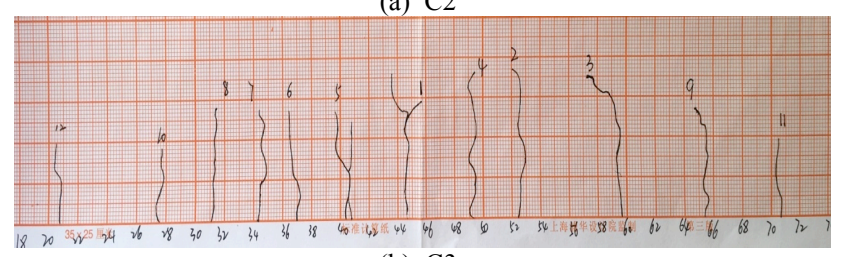

(b) $\mathrm{C} 3$

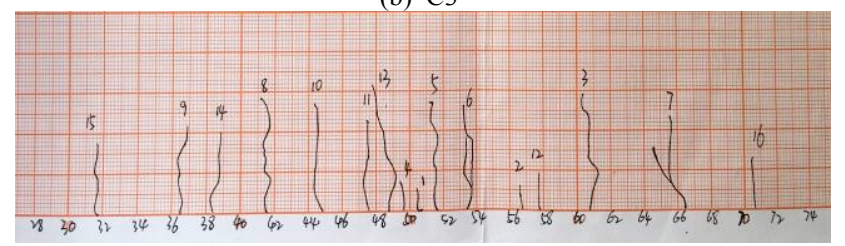

(c) $\mathrm{C} 4$
Fig. 3. Crack distribution in constant-amplitude fatigue test

\subsubsection{Load displacement analysis}

Figures 4(a)-4(c) illustrate that under increasing cyclic loads, the stiffness of the test beams decreased, whereas deflection increased gradually. The growth amplitude of the midspan deflection of the test beams is related to the upper fatigue load limit and number of loads. Deflection first increased before cracking during the early loading process (first 100,000-300,000 loads) and then gradually decreased from the cracking stage to the yield stage. This behavior is indicative of stable growth. As shown in Fig. 4(d), given the same low load limit, the slope of deflection is positively related with the upper limit of the fatigue load. A steep slope represents the drastic growth of deflection. The fatigue life of C4 was only 102,000 loads, and deflection developed more quickly in $\mathrm{C} 4$ than in other beams until failure. This result indicated that overload would significantly deform and severely damage beam structures.

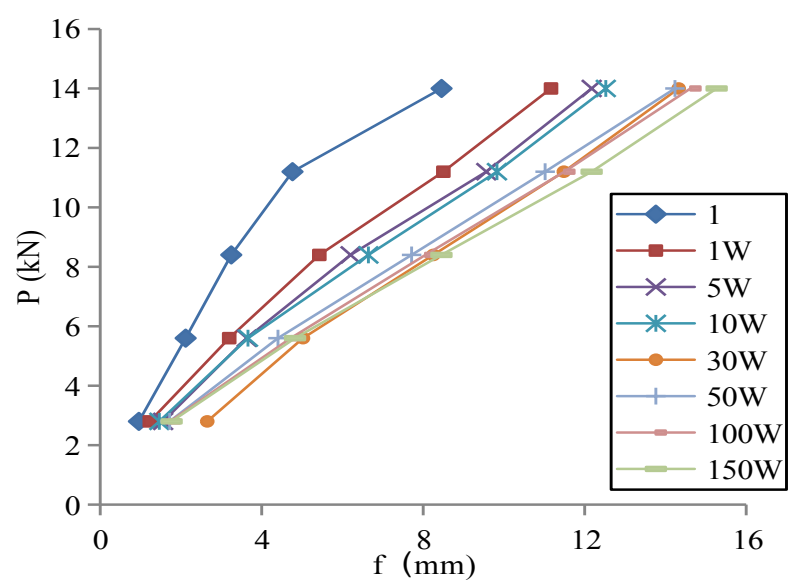

(a) $\mathrm{C} 2$ 


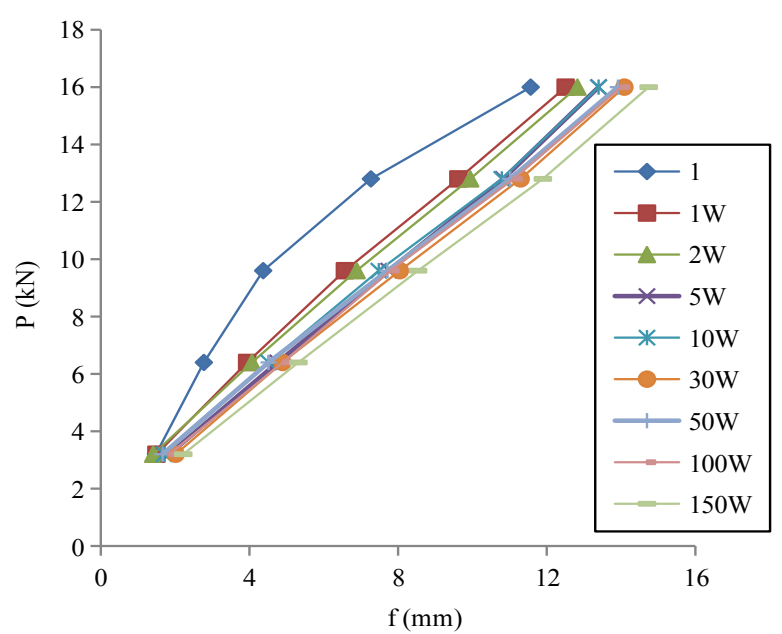

(b) $\mathrm{C} 3$

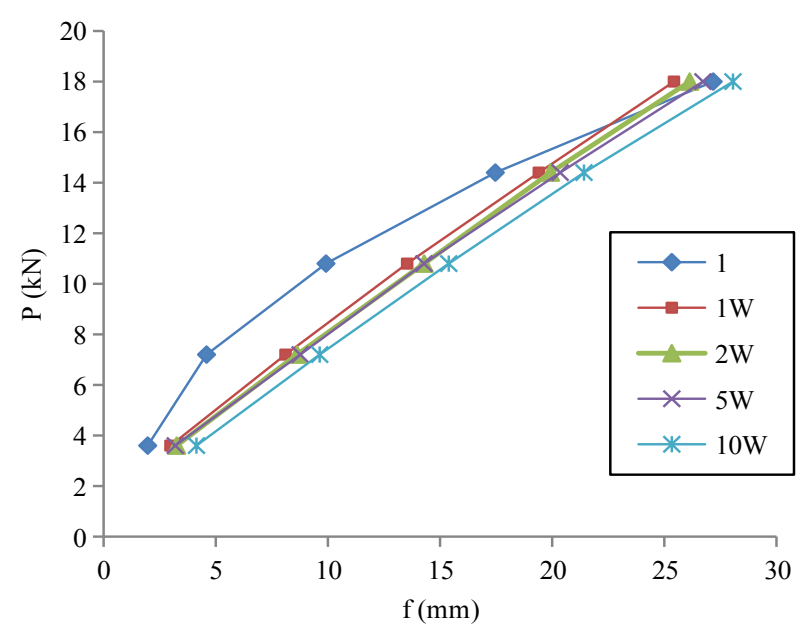

(c) $\mathrm{C} 4$

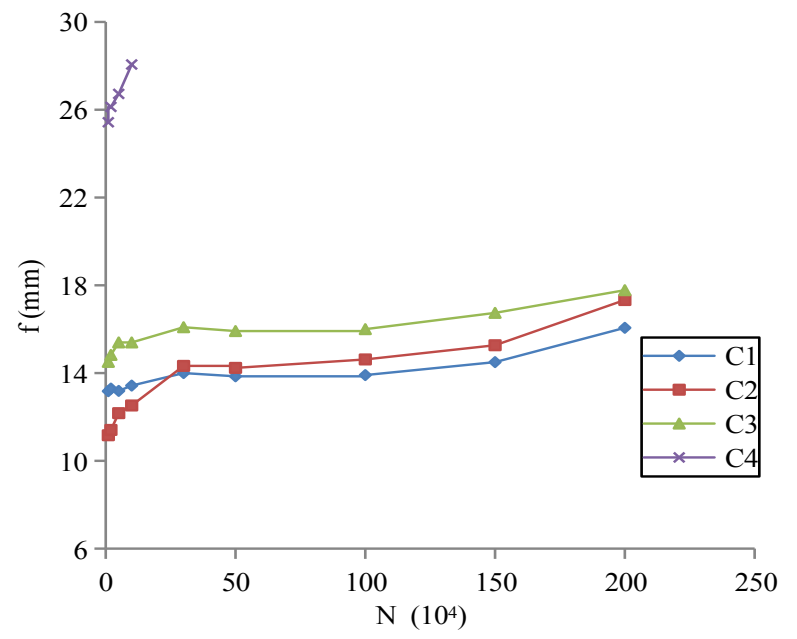

(d) Variation curve of midspan deflection with load cycle Fig. 4. Variation trend of midspan deflection

\subsubsection{Strain analysis of steel bars}

The variation trend of the steel bars is shown in Fig. 5. Comparing $\mathrm{C} 1, \mathrm{C} 3$, and $\mathrm{C} 4$ revealed that the strain growth of steel bars is positively correlated with stress amplitude under same number of loads. After 100,000 fatigue cycles, the strain growth of $\mathrm{C} 4$ was approximately thrice that of $\mathrm{C} 1$ and exhibited exponential growth (Fig. 5). This result indicated that overload could cause the considerable strain growth of steel bars in the bridge structure. Extremely fast strain growth would accelerate the accumulation of fatigue damage and easily cause the fatigue fracture of steel bars. According to the comparison of $\mathrm{C} 1, \mathrm{C} 2$, and $\mathrm{C} 3$, steel bar strain is positively correlated with the number of loads.

The strain variation of prestressed reinforced bars is shown in Fig. 6. The strain development trend of prestressed reinforced bars was generally consistent with those of steel bars under increasing strain. Comparing $\mathrm{C} 1, \mathrm{C} 2$, and $\mathrm{C} 3$ revealed that after 100,000 loads, the strain growths of prestressed reinforced bars in $\mathrm{C} 3$ and $\mathrm{C} 4$ are approximately 2 and 3.5 times that of $\mathrm{C} 1$, respectively. This result implied that high upper fatigue load limit would result in the high proportion of strain growth.

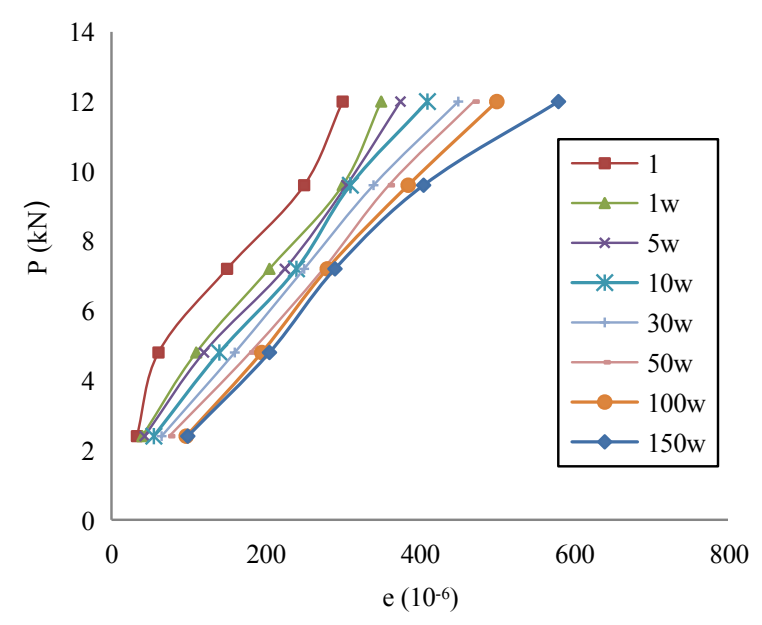

(a) $\mathrm{C} 1$

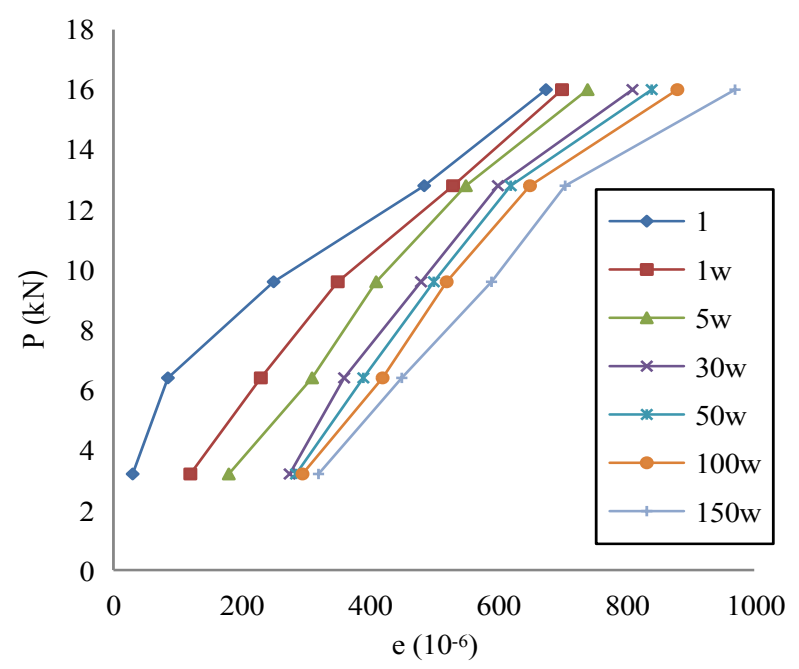

(b) $\mathrm{C} 3$

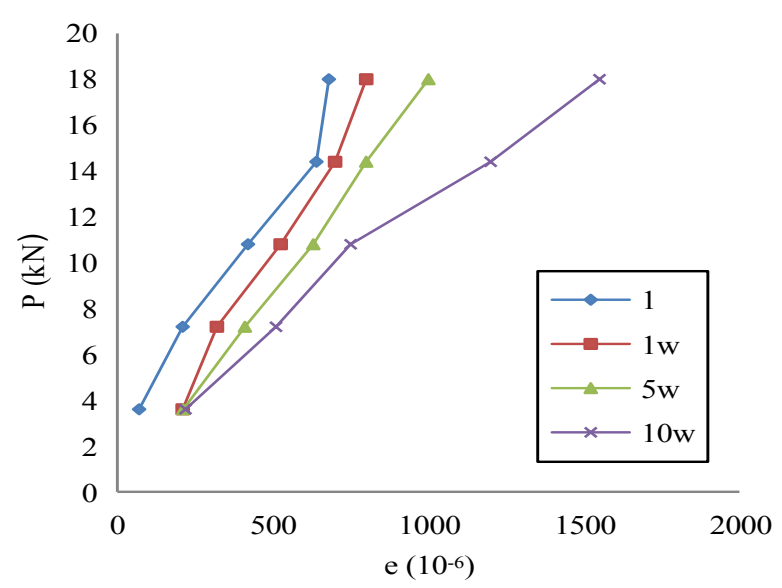

(c) $\mathrm{C} 4$ 


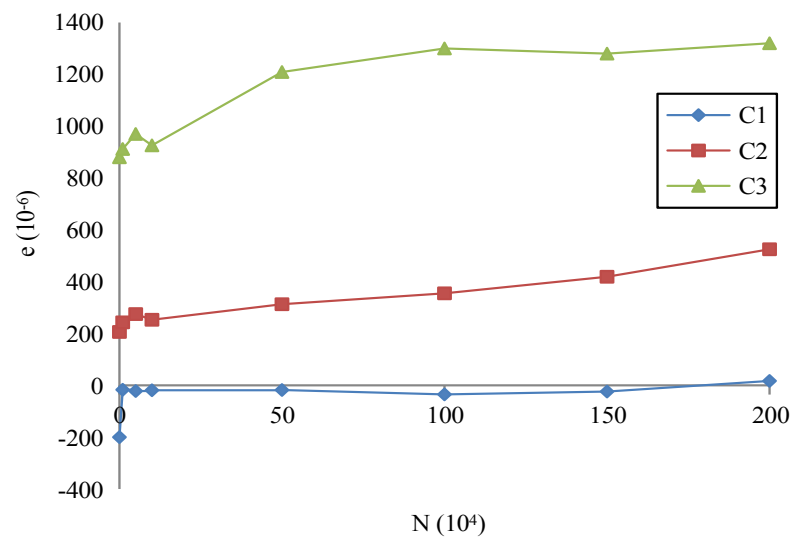

(d) Comparison of the variation trends of fatigue strain in steel bars Fig. 5. Variation trends of fatigue strain in steel bars

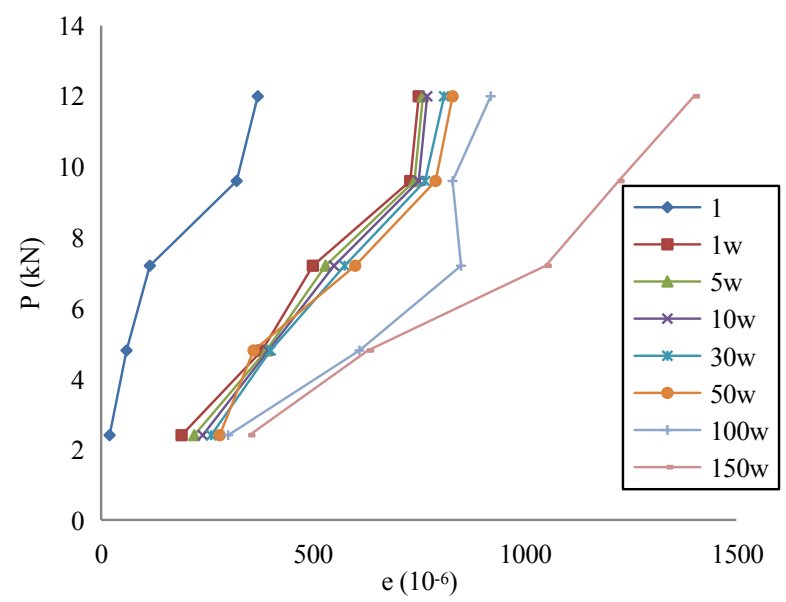

(a) $\mathrm{C} 1$

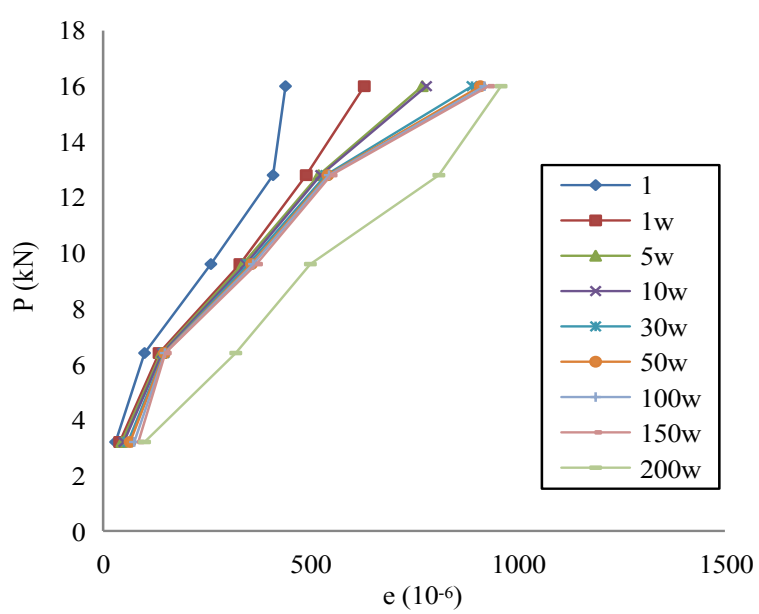

(b) $\mathrm{C} 3$

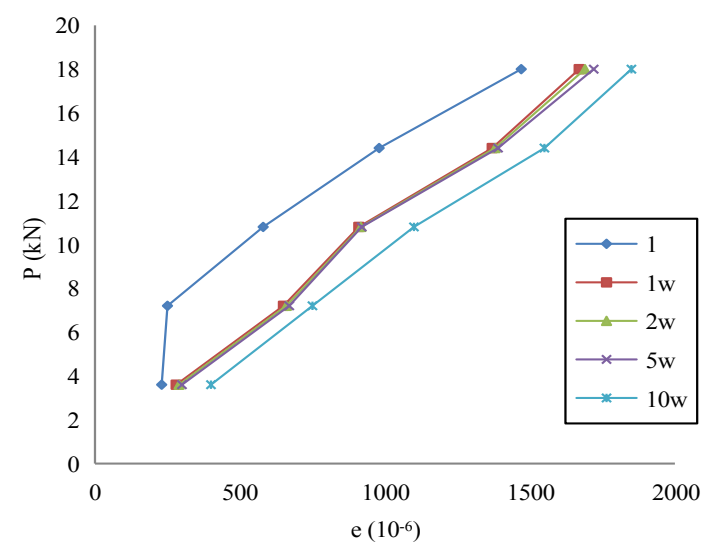

(c) $\mathrm{C} 4$

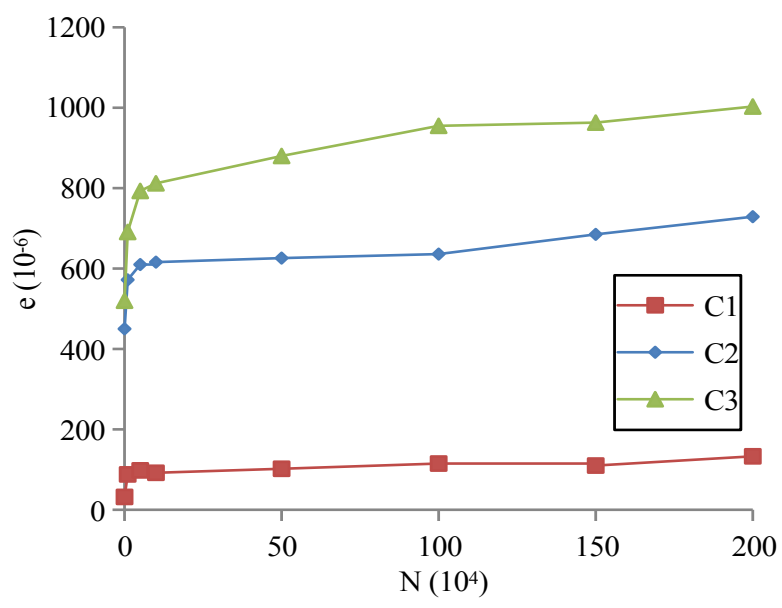

(d) Comparison of the variation trends of fatigue strain of prestressed steel bars

Fig. 6. Variation trends of fatigue strain of prestressed steel bars

\subsection{Results of variable-amplitude fatigue tests 4.2.1 Fatigue failure mode}

The failure modes of test beams characterized through the variable-amplitude fatigue test are similar to those characterized through the constant amplitude fatigue test. All test beams exhibited bending failures, which initiated from the fatigue fracture of the bottom steel bars. Crack width and height increased with increasing numbers of cyclic loading. The major fracture occurred close to the midspan of beams, indicating that loading mode exerts no effect on the final failure mode of structures. Crack comparison showed that the growths of crack width and length significantly accelerated during the secondary fatigue loading process because of fatigue damages accumulated after the first fatigue loading process.

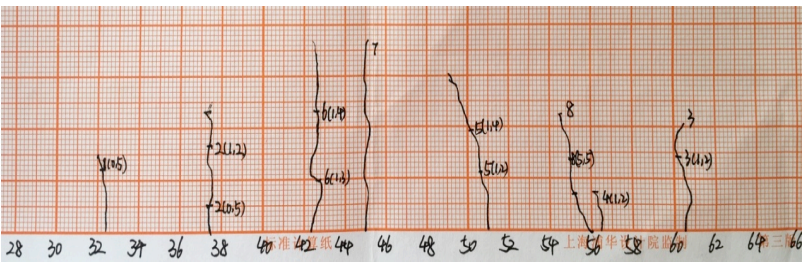

(a) LH1

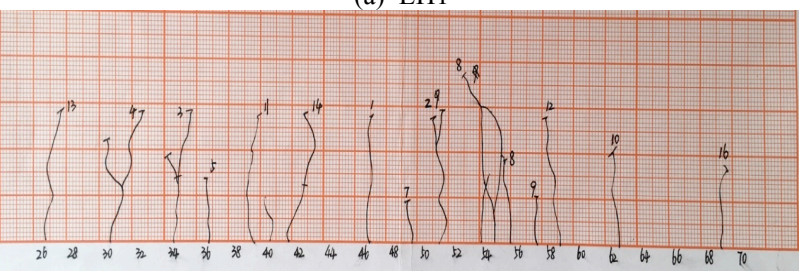

(b) HL1

Fig. 7. Crack distribution characterized through the variable-amplitude fatigue test

\subsubsection{Load displacement analysis}

Results demonstrated that deflection and load exhibit a linear relationship during the secondary fatigue loading process. This relationship generally presented a sparsedense-sparse developmental trend. Deflection significantly changed when the applied load increased from low to high. Therefore, for a bridge structure in normal service, longterm normal load can be viewed as low load, whereas overload is viewed as high load that will cause irrecoverable plastic deformation. In addition, severe overload will result in the considerable accumulation of deflection damages. 


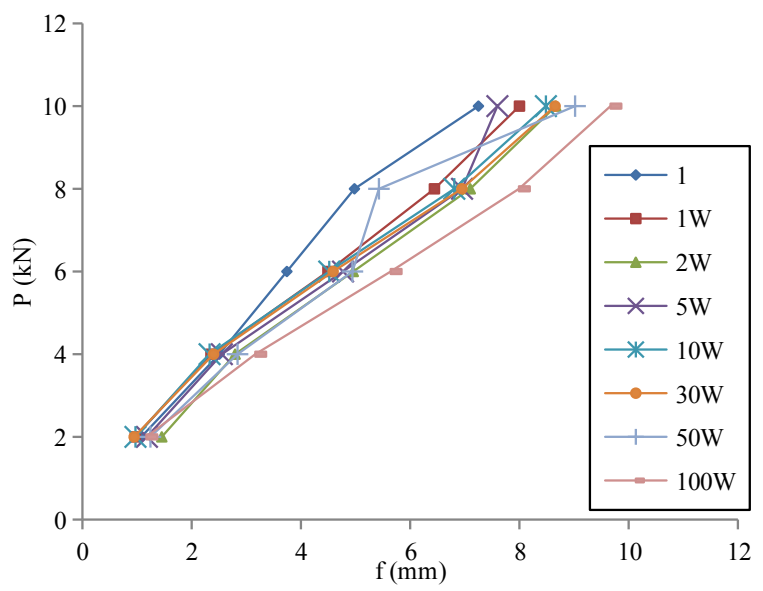

Fig. 8. Load midspan deflection curve of LH1

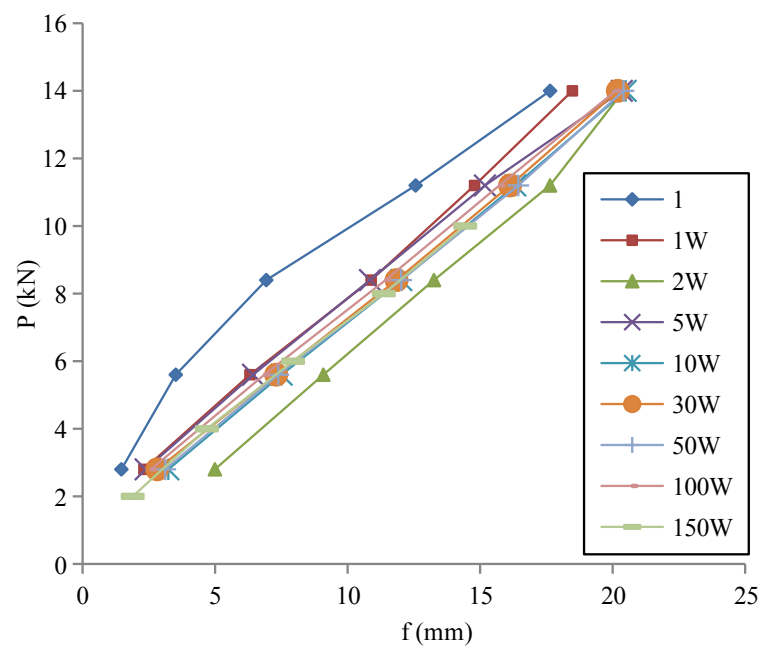

Fig. 9. Load midspan deflection curve of HL1

\subsubsection{Strain analysis of steel bars}

Figures 10 and 11 show that strain growth and load during the secondary fatigue loading process are linearly related. This relationship generally presented a sparse-dense-sparse developmental trend. During the first stage, which involves the accumulation of fatigue damages, increasing the applied load will accelerate strain growth. LH quickly suffered from fatigue failure after 1,080,000 loading cycles, indicating that overloading can rapidly damage beam structures.

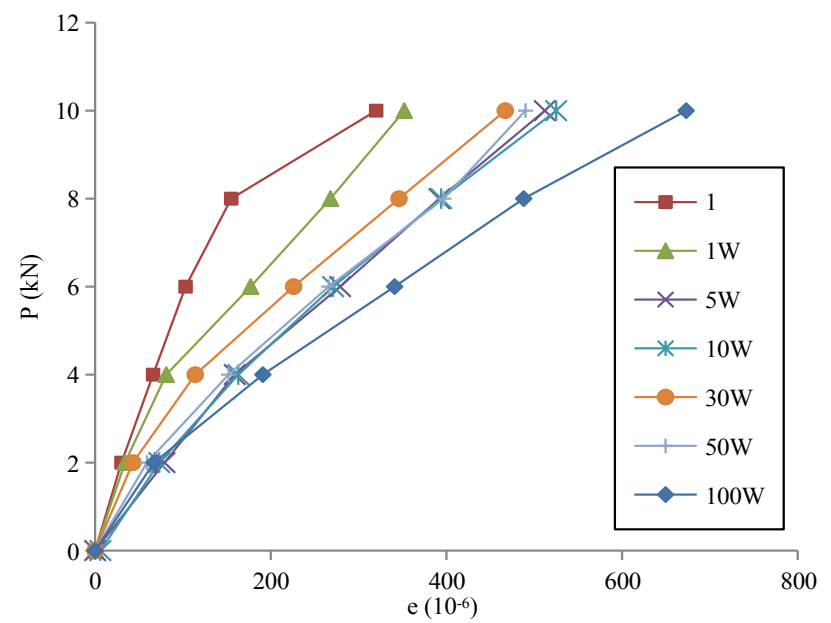

Fig. 10. Load-strain curves of LH1

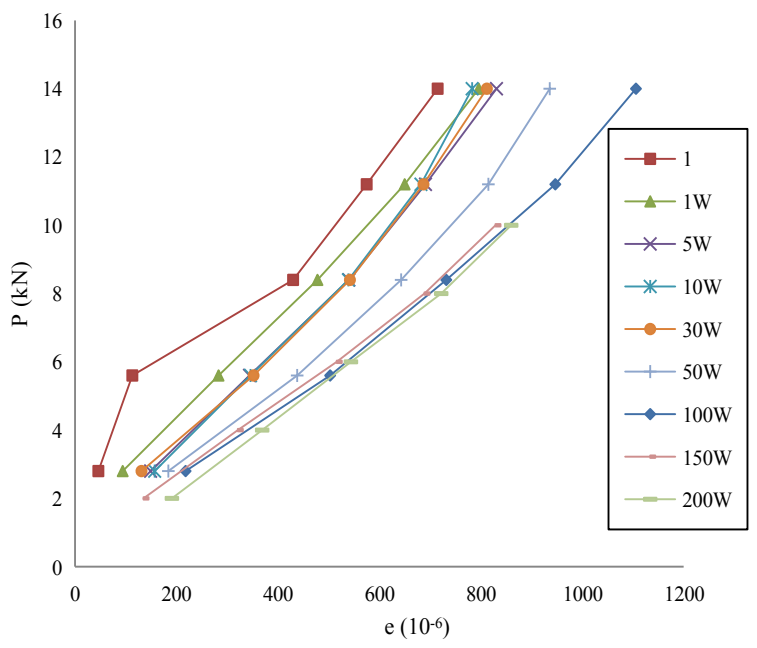

Fig. 11. Load-strain curves of HL1

\subsection{Variation trend of the residual strain of the bottom tensile steel bars}

The strain variation trends of the bottom tensile steel bars are shown in Fig. 12. During fatigue tests, the residual strain of the steel bars increased with increasing load cycles. The variation trend generally conformed to three-stage characteristics. During the early fatigue loading period, the growth rate of the residual strain of the steel bars remained constant, and residual strain changed linearly with the increasing number of loads. The residual strain of steel bars in C4 and C5 developed quickly prior to the beam damage. Subsequently, fatigue failure occurred. According to previous experimental results and analysis, the fatigue fracture of reinforced concrete further causes the fatigue failure of prestressed concrete beams. This result revealed that increasing stress levels would accelerate the strain development of steel bars and cause the early failure of beams.

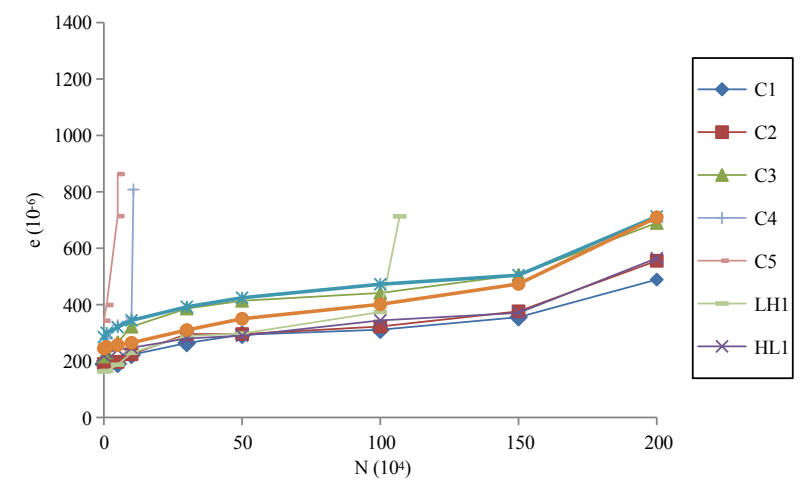

Fig. 12. Developmental trend of the residual strain of tensile steel bars in the beam bottom

\section{Conclusions}

The failure mode of prestressed concrete beams and the fatigue damage development of bridge components were analyzed on the bases of static and fatigue tests to determine the effects of heavy duty on the fatigue performance of prestressed concrete beams. The influences of different load limits and loading methods on fatigue performance were investigated within the framework of the theory of fatigue damage accumulation. The following conclusions were drawn. 
(1) Analyzing fatigue life records and crack propagation in beams revealed that all test beams suffer from bending failures, which begin from the brittle rupture of steel bars under operational load and cyclic overloads. Crack width and height are positively correlated with the number of load cycles. Major fracture frequently occurs close to the midspan of test beams. Deflection growth is determined by the upper load limit under fixed low load and increases quickly when the upper load limit increases. Consequently, deflection growth significantly shortens the fatigue life of concrete beams. Therefore, heavy duty will accelerate the accumulation of fatigue damage by prestressed concrete beams.

(2) Fatigue test results revealed that high overload amplitudes shorten fatigue life. Test beams can only withstand 102,000 and 51,000 loads when the upper load limits are 0.75 and 0.8 times of the ultimate load, respectively.

(3) The midspan deflection of test beams and the strain variation curves of steel bars present a three-stage variation trend under cyclic loading. The fatigue damages of the test beams gradually accumulate and manifest as residual strain growth. The damage caused by variable amplitude fatigue load is more severe than that caused by constant amplitude fatigue load. Therefore, the analysis of the actual durability and safety of beams in service based on constant amplitude fatigue test compared with the actual operation is conservative.

In summary, compared with the fatigue performance analysis of prestressed concrete beams under a conservative load range, which under heavy duty is closer to the fatigue performance of prestressed concrete beams under actual engineering applications. The effects of overload on bridge structure under the variable amplitude fatigue test, which considers cyclic, rather than constant, vehicle loads, are highly accurate. The results of this study can provide references for the safety monitoring, design, and construction of engineering structures. This study still exhibits limitations because it only uses constant amplitude and two-level variable amplitude load to analyze the fatigue performance of actual bridge structures given the uncertainty of vehicle load. For the accurate analysis of the fatigue performance of bridge structures under actual vehicle load, future studies should comprehensively consider the randomness and accuracy of the applied load.

\section{References}

1. Ministry of Transport of the People's Republic of China., "The second national highway census data announcement". Highway, (3), 2002, pp.125-129.

2. Liu, C., Zhu, E., Zhu, X., "Development of prestressed concrete bridges and its durability". Railway Engineering, 11, 2005, pp.112.

3. CCCC Highway Consultants CO. Ltd., "Technical standard of highway engineering". Beijing: China Communication Press, China 2015.

4. Gao, C., Wang, H., Peng, J., "Bridge engineering development and application of complex corrosive environment simulation system". Highways and Automotive Applications, 1 (1), 2012, pp.152-159.

5. Menan, F., Henaff, G., "Influence of frequency and exposure to a saline solution on the corrosion fatigue crack growth behavior of the aluminum alloy 2024". International Journal of Fatigue, 31 (11), 2009, pp.1684-1695.

6. Zeng, D., Wang, G., Xie, J., "Exploratory experimental study on fatigue prestress loss of prestressed concrete beams". Journal of Highway and Transportation Research and Development (English Edition), 8 (2), 2014, pp.37-41.

7. Xin, Q., Dou, Y., Chen, W., "Load spectrum and fatigue life computer analysis of prestressed concrete bridges". International Journal of Security and Its Applications, 9 (7), 2015, pp.247-266.

8. Sieniawska, R., Śniady, P., "Life expectancy of highway bridges due to traffic load". Journal of Sound and Vibration, 140 (5), 1990, pp.31-38.

9. Ruan, X., Zhou, X., Guo, J., "Extreme value extrapolation for bridge vehicle load effect based on synthetic vehicle flow". Journal of Tongji University (Natural Science), 40 (10), 2012, pp.1458-1642, 1485.

10. Meng, Q., Zhao, Z., "Research on the analysis and comparison of the transportation status of a regional freeway based on toll collection data". In: 16th COTA International Conference of Transportation Professionals, Shanghai, China: ASCE, 2016, pp.2241-2251.

11. Pais, J. C., Amorim, S.I.R., Minhoto, M. J. C., "Impact of traffic overload on road pavement performance". Journal of Transportation Engineering, 139 (9), 2013, pp. 837-879.

12. Kihyon, K., Dan, M., Frabgopol., "Bridge fatigue reliability assessment using probability density functions of equivalent stress range based on field monitoring data". International Journal of Fatigue, 32 (8), 2010, pp.1221-1232.
13. Ministry of Transport of the People's Republic of China., "2015 Statistical bulletin of development in transport industry". Beijing: Department of Transportation Comprehensive Planning Department, China, 2016.

14. Li, Q., Wang, C., "Updating the assessment of resistance and reliability of existing aging bridges with prior service loads". Journal of Structural Engineering, 141 (12), 2015, pp.04015072.

15. Walter, P.H., Kilareski., "Heavy vehicle evaluation for overload permits". In: Transportation Research Record 1227. Washington, USA: TRB, 1989, pp.194-204.

16. Zhou, Y., Chen, S., "Dynamic simulation of a long-span bridgetraffic system subjected to combined service and extreme loads". Journal of Structural Engineering, 141 (9), 2015, pp.04014215.

17. Han, W., Wu, J., Cai, C., "Nonlinear dynamic performance of longspan cable-stayed bridge under traffic and wind". Wind and Structures, An International Journal, 20 (2), 2015, pp.249-274.

18. Han, W., Yan, J., Wu, J., "Extra-heavy truck load features and bridge dynamic response based on long term traffic monitoring record". China Journal of Highway and Transport, 27 (2), 2014, pp.54-61.

19. Huang, W., Wang, X., Liu, H., "Overloaded trucking in China and countermeasures". Journal of Highway and Transportation Research and Development, 20 (2), 2003, pp.481-152.

20. Zhang, J., Peng, H., Cai, C. S., "Field study of overload behavior of an existing reinforced concrete bridge under simulated vehicle loads". Journal of Bridge Engineering, 16 (2), 2011, pp.226-237.

21. Oudah, F., EI, H., "Performance of RC beams strengthened using prestressed NSM-CFRP strips subjected to fatigue loading". Journal of Composites for Construction, 16 (3), 2012, pp.300.

22. Barbara, G, Charalambidi., Theodoros C. Rousakis., Athanasios I. Karabinis., "Analysis of the fatigue behavior of reinforced concrete beams strengthened in flexure with fiber reinforced polymer laminates". Journal of Composites for Construction, 20 (5), 2016, pp.69-78.

23. Pokorný, P., Náhlík, L., Hutař, P., “Comparison of different load spectra on residual fatigue lifetime of railway axle". Procedural Engineering, 74, 2014, pp.313-316.

24. Joan R. Casas, Juan D. Gómez., "Load rating of highway bridges by proof-loading". Journal of Civil Engineering, 17 (3), 2013, pp.556-567.

25. Koch, G. C., Brongers, M. P., Thompson, M. P., “Corrosion costs and preventive strategies in the United States". Washington: Federal Highway Administration, USA, 2002. 